\title{
UM MARXISMO DE AFINIDADES ELETIVAS: a aventura sociológica de Michael Löwy
}

\author{
Marco Aurélio Santana*
}

\begin{abstract}
O presente artigo analisa o trabalho de elaboração de Michael Löwy sobre o conceito de "afinidades eletivas", utilizado por Max Weber. Nesse sentido, busca apresentar os avanços por ele trazidos para uma maior definição do conceito e a operatividade de seu uso, bem como algumas das repercussões que indicaram seus possíveis limites em termos de elaboração e operação. Antes, à guisa de preâmbulo, o artigo faz uma apresentação do contexto sociológico de sua aparição mais conhecida, a partir do livro A ética protestante e o "espírito" do capitalismo (EPEC), de Max Weber, que serve de importante base de lançamento para os investimentos de Löwy.
\end{abstract}

PALAVRAS-chave: Afinidades eletivas. Michael Löwy. Max Weber. Ética protestante. Teoria social.

\section{APRESENTAÇÃO}

O trabalho de reflexão, investigação e engajamento de Michael Löwy tem dado contribuições de relevo, marcadas por erudição e profundidade, em diferentes ramos das ciências sociais, como as sociologias do conhecimento, da política, da cultura e da religião. Suas obras têm, já há décadas, a marca da tentativa de aproximações entre sua visão do marxismo e um conjunto de autores, temas e esferas da vida social em uma démarche que, muitas vezes, em um primeiro olhar, pode causar estranhamento.

Tem sido bastante frutífero, inovador e instigante o esforço das tentativas de percepção de "afinidades eletivas" entre, por exemplo, para ficar em algumas: judaísmo e libertarismo (1988), marxismo e cristianismo (1990), marxismo e Weber (1996), socialismo e ecolo-

* Universidade Federal do Rio de Janeiro (UFRJ). Instituto de Filosofia e Ciências Sociais (IFCS). Departamento de Sociologia. Programa de Pós-Graduação em Sociologia e Antropologia.

Largo de São Francisco, n. 1, Sala 416. Centro. Cep. 20.051070. Rio de Janeiro - Rio de Janeiro - Brasil. msantana@ ifcs.ufrj.br gia (2013), e marxismo e anarquismo ${ }^{1}$ (2016). Como o leitmotiv da empreitada indica, as reflexões sobre e a partir da obra de Max Weber têm lhe servido de fio condutor nessa, como ele mesmo já chamou, aventura.

Trabalhar com um dos grandes da teoria social já é uma tarefa difícil; com dois, a dificuldade se torna redobrada. Pode-se imaginar, então, o grau de complexidade da busca de aproximações entre eles. Por óbvio, um investimento desse tipo e porte tende a produzir efeitos teóricos, metodológicos e políticos em variadas constelações, adquirindo seguidores e críticos.

A ideia do presente artigo é, partindo do trabalho de elaboração de Löwy sobre o conceito de "afinidades eletivas", mostrar os avanços que ele traz para uma maior definição do conceito e a operatividade de seu uso, e algumas das repercussões que indicaram seus possíveis limites em termos de elaboração e operação. Antes, à guisa de preâmbulo, faz-se importante uma apresentação do contexto sociológico de sua aparição mais conhecida, a partir do livro $A$ ética protestante $e$

${ }^{1}$ Essa obra foi publicada em coautoria com Olivier Besancenot. 
o "espírito" do capitalismo (EPEC) de Max Weber, que serve de importante base de lançamento para os investimentos de Löwy. ${ }^{2}$

\section{WEBER E AS AFINIDADES ELETIVAS}

Publicado por Weber em 1904-1905 e revisto e ampliado por ele em 1920, a EPEC sofre muitas alterações que podem ser creditadas ao desenvolvimento intelectual de seu autor. ${ }^{3}$ Apesar de mudanças que ajudam a esclarecer alguns pontos entre as duas edições, decorrentes, principalmente, da forte polêmica que o livro produziu, lançando Weber em duros e, às vezes, até rudes debates (Weber, 2001), um ponto que permaneceu pouco desenvolvido foi o conceito de "afinidades eletivas". Tem-se uma operação direta dele nas análises de Weber, mas não uma definição clara e precisa desse operador.

É interessante notar que a obra de Weber é conhecida, por variadas razões, por uma não sistematicidade, mas, em outras situações, momentos e casos, nela existem definições claras dos operadores propostos e usados por ele, inclusive na EPEC. O mesmo não acontece com o conceito de "afinidades eletivas". ${ }^{4}$ Esse, diga-

${ }^{2}$ Howe (1978) indica que o primeiro uso do conceito se $\infty$ deu, um ano antes da publicação da EPEC, no famoso ar$\underset{-1}{\infty}$ tigo sobre a objetividade do conhecimento nas ciências ㄱ. sociais (Weber, 2008). Agradeço à University of California $\dot{\circ}$ at Berkeley por ter me garantido o acesso à grande parte do \& material referido neste artigo, principalmente via JSTOR. . Isso foi possível graças ao Estágio Sênior da CAPES, reali$\sum^{\pi}$ zado em 2017 e 2018, junto a essa instituição.

$\infty^{3}$ Pierucci (2004, p. 9), na verdade, seriam "tantos e de $\stackrel{\infty}{\sim}$ tamanhos tão diversos os acréscimos feitos por Weber à ^ segunda edição”, que teríamos mesmo duas versões da ลิ EPEC. Para ele, "Chamemos então de versão original aqueف la publicada na revista Archiv, em duas partes e em dois i. momentos consecutivos, 1904 e 1905. E chamemos de $\infty$ versão final a edição de 1920 (ano também final da vida

¿ de Weber), aquela que se permite dizer as coisas numa lin-

$\therefore$ guagem mais precisa na forma e mais segura na atitude".

๓ De todo modo, segundo o próprio Weber (2004, p. 26), "A

$>$ todo aquele que (contra minha expectativa) se interessar,

ธิ deixo a tarefa de cotejar as duas versões para se conven-

đ cer de que: não suprimi, alterei, atenuei uma única frase

sequer do meu ensaio que contivesse qualquer afirmação

$\varpi$ essencial no conteúdo, nem acrescentei argumentos que

Tí no conteúdo divergissem da primeira versão. Não havia

공 motivo algum para fazê-lo". Não seria aqui o lugar de de-

senvolver essa questão, mas, segundo Nielsen (2003), as

mudanças acabaram efetivamente por alterar certos senti-

dos expostos na primeira versão.

${ }^{4}$ McKinnon (2010, p. 110) lembra que o próprio Weber, mos, ponto cego nas conceituações de Weber foi apontado por Howe (1978), Thomas (1985) e Löwy (1999; 2004). ${ }^{5}$ Esses autores, com resultados diferentes, não só chamam a atenção para essa questão como tentam desenvolver reflexões a partir daí.

Como várias outras obras de seu porte, a EPEC traz um conjunto de questões que não apenas caracterizam a démarche weberiana, como vão auxiliar na constituição de diversos campos nas ciências sociais. São possíveis diferentes entradas e possíveis ângulos pelos quais se pode penetrar na obra. E isso foi feito ao longo de sua trajetória de produção, circulação e recepção ao longo do tempo, dos contextos e das perspectivas envolvidas.

Além disso, a carreira do livro se fez para dentro do universo das ciências sociais, mas também para fora dele, alcançando um público muito mais amplo e variado. Nesse sentido, Pierucci chama a atenção para o fato de que a EPEC

... se mantém a mais lida das obras de Weber. No ano
2000, em listagens de livros que mostravam "os 10
mais lidos" do século XX, lá estava A ética protes-
tante, obra sempre muito bem colocada em ranques
do gênero. Sua popularidade editorial é tamanha e
tão estável, que mesmo na mente de um universitá-
rio que curse ciências sociais, ela pode muito bem
se representar como a obra "mais importante” do
mais importante sociólogo alemão, mas na opinião
da maioria dos sociólogos não é. Numa pesquisa de
opinião feita em 1998 pela ISA, solicitando a seus
membros que apontassem qual a obra de Sociologia
mais importante e influente do século XX, Econo-
mia e Sociedade saiu vencedora por ampla margem
(Pierucci, 2008, p. 41).

Um dos pontos importantes trazidos pela obra, segundo Allen (2017, p. 32), encontra-se no fato de que ela "deslocou a sociologia das preocupações com padrões evolucionistas

quando do primeiro uso de "afinidade", sugeria que "valia a pena "aceitar, por ora, este termo superficialmente ambíguo”".

${ }^{5}$ A importância do conceito já havia sido sinalizada por Gerth e Mills (1982), em 1946, em sua organização de textos de Weber nos Ensaios de Sociologia. Contudo, ali não se aponta qualquer questionamento ou indefinição do mesmo. 
para a abordagem comparativa”. ${ }^{6}$ De certa forma, até então, aquelas preocupações se davam a partir de esquemas universais nos quais as sociedades se moviam através de um conjunto de estágios. Nesse sentido, "Weber muda o foco para a análise comparativa, buscando identificar o que seria único e distinto sobre sociedades particulares".

Por sua vez, Kalberg (1996, p. 49) indica vários outros alcances da EPEC. Segundo ele, para além de oferecer "muito mais do que uma análise das origens de um ethos econômico moderno e mesmo muito mais do que um estudo das formas pelas quais ideias influenciaram o desenvolvimento do capitalismo moderno no Ocidente", essa obra de Weber deveria ser compreendida "também em termos de suas muitas contribuições teóricas à sociologia”.

Entre essas contribuições, Kalberg (1996) aponta o tratamento das relações entre história e sociologia, tradição e mudança social, interesses econômicos e forças culturais, capitalismo e valores, níveis micro e macro de análise, passado e presente, e ação individual e formação de grupos.

Como já é quase um senso comum, há, na EPEC como em vários outros momentos e partes das obras de Weber, um intento de, como ele mesmo indicava, "crítica positiva ao materialismo histórico" (Gerth; Mills, 1982, p. 82). Esse intento, que atravessa suas obras, fez com que Weber fosse tomado como uma espécie de antídoto ao pensamento de Marx e ao marxismo, tendo sido utilizado como arma de combate para quase todos aqueles que buscavam criticar ou até mesmo erradicar Marx e o marxismo do cenário intelectual. Por óbvio, essas visões forçaram a mão, empurrando a perspectiva esposada por Weber para certo corner, digamos, muitas vezes distante de suas preocupações efetivas. $^{7}$

Será o próprio Weber (2008, p. 118) que,

${ }^{6}$ Todas as citações das obras referidas em inglês e francês neste artigo são de tradução do autor.

7 Para uma visão mais detalhada sobre o "diálogo implícito" entre Weber e Marx, ver Löwy $(1971,1989)$. em determinado momento, mesmo que o trazendo de forma interessada para seu campo, indica seu reconhecimento elogioso à obra de Marx, sobretudo à sua capacidade de construções de "tipos ideais". Para ele, Marx, "este grande pensador", seria o exemplo "de longe o mais importante de construções de tipo ideal”. Ainda que não só, muito do que chamava de materialismo histórico ingênuo tinha a ver com formulações de Karl Kautsky, ${ }^{8}$ que considerava esquemáticas.

A partir da tentativa de explicitação dos nexos "entre certas formas da fé religiosa e certas formas da ética profissional” (2004, p. 83), que, segundo o próprio Weber, já teriam sido avançadas, ainda que de forma limitada, por Bernstein, ${ }^{9}$ a EPEC apresenta uma hipótese de desenvolvimento do capitalismo moderno.

O capitalismo hodierno, dominando de longa data a vida econômica, educa e cria para si mesmo, por via da seleção econômica, os sujeitos econômicos empresários e operários - de que necessita. E, entretanto, é justamente esse fato que exibe de forma palpável os limites do conceito de "seleção" como meio de explicação de fenômenos históricos. Para que essas modalidades de conduta de vida e concepção de profissão adaptadas à peculiaridade do capitalismo pudessem ter sido "selecionadas", isto é, tenham podido sobrepujar outras modalidades, primeiro elas tiveram que emergir, evidentemente, e não apenas em indivíduos singulares isolados, mas sim como um modo de ver portado por grupos de pessoas (Weber, 2004, p. 83).

Logo em seguida, Weber sinaliza diretamente contra que tipo de concepção ele se posicionaria.

${ }^{8}$ É conhecida a importância e o papel desempenhado por Karl Kautsky no cenário do marxismo da época. Na nota 188 da EPEC, página 246, Weber indica que "[Em outra oportunidade] falaremos da exposição [extremamente esquemática] de Kautsky sobre o movimento anabatista e sua teoria do 'comunismo herético' (no primeiro volume da mesma obra)". Weber tece esse comentário sobre Karl Kautsky, após valorizar as contribuições apresentadas por Eduard Bernstein.

${ }^{9}$ Segundo Weber (2004, p. 269), na nota 278, a quem Bernstein teria mesmo emprestado material sobre o tema, "Seus argumentos foram os primeiros a sugerir essas importantes conexões. Mas o nexo é bem mais amplo do que ele supõe. Pois o decisivo não era a simples acumulação de capital, mas a racionalização ascética da vida profissional como um todo". 
Portanto, é essa emergência de um modo de ver que se trata propriamente de explicar. Só alhures teremos ocasião de tratar do pormenor daquela concepção do materialismo histórico ingênuo segundo a qual "ideias" como essa são geradas como "reflexo" ou "superestrutura" de situações econômicas (Weber, 2004, p. 48)

Contudo, Weber alerta para o equívoco de uma condução que simplesmente substitua o que seria uma visão determinista e limitada por outra do mesmo tipo, apenas partindo de perspectiva diferente. Segundo ele,

... não se deve de forma alguma defender uma tese tão disparatadamente doutrinária que afirmasse por exemplo: que o "espírito capitalista” (sempre no sentido provisório dado ao termo aqui) pôde surgir somente como resultado de determinados influxos da Reforma [ou até mesmo: que o capitalismo enquanto sistema econômico é um produto da Reforma]. Só o fato de certas formas importantes de negócio capitalista serem notoriamente mais antigas que a Reforma impede definitivamente uma visão como essa (Weber, 2004, p. 82).

Mas, então, do que se trataria finalmente e qual seria seu projeto em termos efetivos?

Trata-se apenas de averiguar se, e até que ponto, influxos religiosos contribuíram para a cunhagem qualitativa e a expansão quantitativa desse "espírito" mundo afora, e quais são os aspectos concretos da cultura assentada em bases capitalistas que remontam àqueles influxos (Weber, 2004, p. 82).

Mais do que a substituição de uma interpretação causal "materialista" por outra "espiritualista”, Weber, na passagem, talvez não por acaso, fecha a EPEC, o que lhe dá considerável destaque, indicando a condição de possibilidade das duas e $\therefore$ qual teria sido seu intento ao longo da obra.

[O que aqui se tentou foi apenas, se bem que num ponto único, mas importante, fazer remontar a seus motivos o fato e o modo de sua influência.] Mas depois, ainda seria preciso trazer à luz o modo como a ascese protestante foi por sua vez influenciada, em seu vir-a-ser e em sua peculiaridade, pelo conjunto das condições sociais e culturais, também e especialmente as econômicas. Porquanto, embora o homem moderno, mesmo com a melhor das boas vontades, geralmente não seja capaz de imaginar o efetivo al- cance da significação que os conteúdos de consciência religiosos tiveram para a conduta de vida, a cultura e o caráter de um povo, não cabe, contudo, evidentemente, a intenção de substituir uma interpretação causal unilateralmente "materialista" da cultura e da história por uma outra espiritualista, também ela unilateral (Weber, 2004, p. 167). ${ }^{10}$

Em vários momentos de seus trabalhos, Weber deu ênfase, a mais ou a menos, ao que poderia ser a relevância das duas perspectivas. ${ }^{11}$ De todo modo, nas últimas linhas da EPEC, ele assinala a possibilidade de ambas. Contudo adverte que, "se tiverem a pretensão de ser, não a etapa preliminar, mas a conclusão da pesquisa, igualmente pouco servem à verdade histórica." (Weber, 2004, p. 167).

Em todas essas passagens, depreende-se a importância das "afinidades eletivas" na efetivação dos nexos que Weber busca reconhecer "entre certas formas da fé religiosa e certas formas da ética profissional” (Weber, 2004, p. 83). Na edição brasileira de 2004 , o termo "afinidades eletivas" aparece no fim do terceiro capítulo da primeira parte. Pode-se ver como, diferentemente de outros termos importantes na operação Weberiana presentes na obra, ele não é alvo de uma definição explícita. ${ }^{12}$ Fica claro que ele tem centralidade no fazer-se analítico weberiano, pois se opera com ele, mas não se lhe dá maior definição.

Em face da enorme barafunda de influxos recíprocos entre as bases materiais, as formas de organi-

${ }^{10}$ Schluchter (2005, p. 669-670) indica que, na EPEC, descobre-se o modelo pluridimensional de análise de Weber. Nesse estudo, para ele, "Weber apoia sua pesquisa em um dos flancos da relação de causalidade, como ele mesmo dirá mais tarde [...] - a saber: a influência de uma religião de cultura sobre a disposição do espírito econômico e não o caráter condicionado pelas classes (e as ordens) desta religião de cultura. Entretanto, uma apresentação formal não deve ocultar um estado intermediário - a adaptação do modelo religioso de interpretação ao desejo de certeza de salvação por aquele que crê. Uma dupla mudança de nível é, então, necessária para explicar a aparição do "espírito" do capitalismo moderno.

${ }^{11}$ Gerth e Mills (1982, p. 82) chamam a atenção para o fato de que, diferentemente da EPEC na qual iniciaria com concepções religiosas, Weber, "Em seus últimos ensaios [...] começa sua análise da China, por exemplo, com capítulos sobre as bases econômicas".

${ }^{12}$ Como veremos posteriormente neste texto, isso abrirá, entre os intérpretes de Weber, um conjunto de análises, indagações e desenvolvimentos acerca da questão, estando Michael Löwy aí incluído. 
zação social e política e o conteúdo espiritual das épocas culturais da Reforma, procederemos tão só de modo a examinar de perto se, e em quais pontos, podemos reconhecer determinadas "afinidades eletivas" entre certas formas da fé religiosas e certas formas da ética profissional. Por esse meio e de uma vez só serão elucidados, na medida do possível, o modo e a direção geral do efeito que, em virtude de tais afinidades eletivas, o movimento religioso exerceu sobre o desenvolvimento da cultura material. Só depois [quando isso estiver estabelecido de forma razoavelmente inequívoca] é que se poderá fazer a tentativa de avaliar em que medida conteúdos culturais modernos são imputáveis, em sua gênese histórica, àqueles motivos religiosos e até que ponto se devem a outros fatores (Weber, 2004, p. 83).

Gerth e Mills (1982) chamam a atenção que o conceito de "afinidades eletivas" seria decisivo na perspectiva de Weber, a de relacionar "ideias" e "interesses materiais" no que seria uma forma mais complexa, opondo-se às visões de mera "correspondência", "reflexo" ou "expressão". Nesse sentido, qualquer concepção determinista estaria interditada. McKinnon (2010), por sua vez, assinala que essa visão de Gerth e Mills (1982) foi bastante influente na sociologia americana do pós-guerra, servindo de certa contraposição às posições marxistas. Ele chama a atenção também para o fato de que, em muitos momentos de sua obra, Weber usa a mesma noção não apenas para relacionar "ideias" e "interesses", mas também "ideias" e "ideias", bem como "interesses" e "interesses".

Ainda que não tenha produzido propriamente um debate sobre ele, o uso do termo "afinidades eletivas" deu origem a variada interpretação, seja pela verificação ou não de sua reduzida definição, seja também por conta das vias de sua incorporação por Weber. Não caberia aqui um detalhado olhar sobre a trajetória do termo "afinidades eletivas". Isso, ainda que guardando as diferenças entre eles, já foi feito de forma até exaustiva, entre outros, por Howe (1978), Thomas (1985), Löwy (1996) e McKinnon (2010).

A partir desses estudos, pode-se traçar uma trajetória que teria se desenvolvido desde a alquimia medieval, passando, entre outras, pelas químicas francesa e sueca do século XVIII e pela literatura alemã do século XIX, via Goethe. Weber incorporaria o termo que, de certa forma, já tinha ampla circulação nos meios intelectuais de sua época, deslocando-o para o interior das ciências sociais. ${ }^{13}$

O trabalho Howe (1978, p. 373) talvez seja o primeiro que sinaliza a informalidade e a pouca definição que Weber dá às "afinidades eletivas", indicando que o químico sueco Torborn Bergman, ainda que não tenha sido seu criador, foi um dos mais famosos expoentes da teoria da afinidade eletiva. ${ }^{14}$ Em seu livro, $D e$ attractionibus electivus, de 1775, que chegaria à Alemanha em 1783 e seria traduzido como Wahlverwandtschaft ("afinidade eletiva"), ele define o que seria "afinidade eletiva":

Suponha-se que A seja uma substância pela qual outras substâncias heterogêneas a, b, c e d têm uma atração; suponha-se ainda que "A" combinado com "c" à saturação (esta união se chamaria "Ac") deve, com a adição de "b", tender a unir-se com "b" excluindo "C". "A" é então dito atrair "b" mais fortemente do que "c", ou de ter uma atração eletiva mais forte por ele. Por último, deixemos que a união "Ab", com a adição de "a", seja quebrada, e "b" seja rejeitado, e "a” seja escolhido em seu lugar. Daí, tem-se que "a" excede "b" em poder atrativo e teremos uma série de $\mathrm{a}, \mathrm{b}, \mathrm{c}$ no que tange à eficácia. $\mathrm{O}$ que eu chamo de atração, outros denominam de afinidade (Howe 1978, p. 373)

${ }^{13}$ Howe (1978, p. 370-371) sinaliza para o fato de que os contemporâneos de Weber consideravam uma rica expressão do conflito entre a ordem natural e a ordem social e moral. Conhecer o significado de "afinidades eletivas" era fazer parte de uma determinada "ordem de discurso" de uma elite humanisticamente educada. Contudo, aos demais, poderia soar absurda e uma contradição a junção dos dois termos "uma vez que Verwandtschaft (afinidade) denotava relação de sangue, enquanto Wahl (eletiva) sugeria uma escolha nessas matérias.”.

${ }^{14}$ Segundo Howe (1978, p.374) as ideias de afinidade e afinidade eletiva começam sua trajetória no século XIII, com o trabalho do alemão Albertus Magnus, impresso no século XVI. Já no século XVII, “o termo era usado com alguma frequência”. Ele está presente também, no século XVII, por exemplo, em formulacões do alquimista ou químico alemão Johann Glauber. No século XVIII, o químico francês Etienne-Francoise Geoffroy "deu um passo importante na sua consolidação ao propor uma lei com relação às diferentes afinidades observadas na química entre diferentes substâncias”. Em 1775, dar-se-ia o ápice do desenvolvimento da teoria da afinidade eletiva na química, com o trabalho do químico sueco Torborn Bergman. Löwy (1999) inclui o trabalho do holandês Hermanus Boerhave, da primeira metade do século XVIII, nessa trajetória. 
Seguindo o percurso de apropriação e de uso do termo, bem como de seu sentido, Howe (1978) indica que será essa ideia a incorporada como uma metáfora química por Goethe, em seu romance Afinidades Eletivas, de 1809, e também que depois será usada por Weber em diversos momentos de suas análises sociológicas. E, a partir daí, vai seguir outra longa carreira no interior das ciências sociais.

\section{LÖWY E AS AFINIDADES ELETIVAS}

Caberia, agora, verificar em maior detalhe a análise de Löwy sobre a questão. Dois de seus artigos (Löwy, 1999, 2004) tratam mais diretamente do conceito de "afinidades eletivas". No primeiro, ele traça a trajetória do conceito, da alquimia às ciências sociais, dando ênfase ao uso dele feito por Weber, e, aí, já indicando suas limitações. Mais que isso, há um esforço importante e produtivo, apresentando um desenvolvimento na elaboração do conceito, bem como a apresentação de como o próprio Löwy o utiliza em suas análises, fornecendo importante exemplificação de como faz o conceito trabalhar. No segundo, o foco é centrado nas questões trazidas pelo uso weberiano, apresentando os contextos e as formas pelas quais

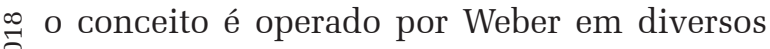
momentos de suas análises.

do, como já mencionamos, a importancia do do, como já mencionamos, a importância do conceito na obra de Weber e terem buscado elucidações, debates e elaborações, Löwy será aquele que não só se deterá mais no tratamen¿ to dele, bem como será aquele que buscará uti$\infty$ gundo ele, ainda que não se deseje, com isso, substituir outros paradigmas analíticos, explicativos ou compreensivos, "o conceito de afinidade eletiva pode constituir um novo ângulo de abordagem, até então pouco explorado, no campo da Sociologia da Cultura" (Lowy 2004, p. 102).
A forma ativa com que faz suas aproximações e operações com a perspectiva de Weber precisa ser assinalada, para além daquela que já faz quanto ao conceito de "afinidades eletivas". Não nos parece que se tenha uma "incorporação" passiva e acrítica de Weber. ${ }^{15}$ Antes se tem uma aproximação que mantém distância crítica sobre diversos aspectos. Löwy aponta os limites de certos postulados metodológicos de Weber, como, por exemplo, o da neutralidade axiológica nas ciências sociais (1987), ou nos limites e problemas das formulações de Weber acerca do desenvolvimento do capitalismo, frente à proposição avançada por Marx 1971 e 2002.

Na percepção de Löwy (1996, p. 432), apesar das claras diferenças reais de teoria e método, e, mais ainda, políticas, entre Marx e Weber, é possível buscar convergências, principalmente quando se trata dos efeitos do capitalismo e de uma crítica a ele. Em suas próprias palavras, o programa seria uma apropriação "de conceitos Weberianos como ferramentas analíticas complementares à dialética marxiana". A ideia seria a de "desenvolver uma crítica mais profunda e (muitas vezes) mais radical do capitalismo". Nesse sentido, o conceito de marxismo weberiano mostraria sua relevância teórica e prática, tendo "significância heurística e política".

No trato com o conceito de "afinidades eletivas” usado por Weber, Löwy (1999) traça o percurso seguido, como já dissemos, por outros autores. Contudo, dá ênfase especial à perspectiva dos alquimistas sobre o processo de "afinidades eletivas". Segundo, por exemplo, o alquimista holandês Hermanus Boerhave, com forte carga metafórica sentimental e erótica, ocorre a atração dos elementos, sua fusão, exclusão e a produção de elementos novos a partir daí. Tal visão será a incorporada por Goethe. Essa "novidade”, surgida do proces-

\footnotetext{
15 Essa postura irrequieta, ou, como já se disse, insubordinada, tem sido sua marca também, diga-se, dentro da tradição marxista e na lida com a obra marxiana.
} 
so, se torna de interesse central para Löwy. ${ }^{16}$ Nesse sentido, ele indica que, no uso weberiano, "se guarda a acepção antiga de escolha recíproca, atração e combinação, mas a dimensão da novidade parece desaparecer.” (Löwy, 1999, p. 43).

Para Löwy (1999, p. 43), o conceito é importante no construto weberiano, tendo em vista que se trataria de ultrapassar "a abordagem tradicional em termos de causalidade e de contornar, assim, o debate sobre a primazia do 'material' ou do 'espiritual'”. É a partir dessa mirada que Weber buscaria dar conta das relações complexas e sutis entre "a ética protestante e o 'espírito' do capitalismo".

Na visão de Löwy, "Weber busca mostrar a existência de elementos convergentes e análogos entre os dois termos". E, a partir dessas analogias profundas, "uma relação de afinidade eletiva entre a ética protestante e o espírito do capitalismo vai se desenvolver, do século XVII ao XIX, na Holanda, na Inglaterra e nos Estados Unidos" (Löwy, 1999, p. 43).

Será graças a essa relação de afinidade eletiva que "a concepção puritana de existência vai favorecer a tendência a uma vida burguesa economicamente racional e vice-versa" (Lowy, 1999, p. 43). Em termos dos resultados de seus procedimentos, Weber nos remeteria, assim, para "uma relação interna rica e significativa entre duas configurações” (Lowy, 1999, p. 44).

De certa forma, o que Löwy faz até aqui seria quase uma descrição do uso weberiano do procedimento. Contudo, ele se deslocará dessa descrição para um esforço de elaboração detalhada do conceito. Partindo, a um só tempo, do uso weberiano e da história anterior do termo, Löwy sugere, inclusive, uma definição:

Trata-se do processo pelo qual duas formas culturais - religiosas, literárias, políticas, econômicas etc. - entram, a partir de certas analogias ou correspondências estruturais, em relação de influência recíproca, escolha mútua, convergência, simbiose e mesmo, em certos casos, fusão (Löwy, 1999, p. 44).

${ }^{16}$ Löwy indica que, em Goethe, incorporando a fórmula de Boerhave, haveria afinidade eletiva quando dois seres ou elementos se buscam um ao outro, se atraem, se combinam e, em seguida, ressurgem dessa união íntima de uma forma renovada e imprevista.
Em seu trabalho de elaboração, Löwy assinala que a afinidade eletiva comporta múltiplos níveis ou graus. Ele indica que esses níveis seriam quatro. O primeiro, o de uma afinidade pura e simples, aquela de parentesco espiritual. Aqui, tratar-se-ia de uma correspondência ainda estática. Teríamos a "possibilidade", mas ainda não a "necessidade de uma convergência ativa, de uma atração eletiva”. As condições históricas e sociais concretas seriam fundamentais para a dinamização do processo (Löwy, 1999, p. 44).

O segundo nível seria aquele em que "a eleição, a atração recíproca, a escolha mútua de duas configurações socioculturais conduzem a certas formas de interação, de estimulação recíproca e convergência” (Löwy, 1999, p. 44). Se elas eram estáticas no nível um, nesse segundo nível, teríamos um começo de dinamização de analogias e correspondências. Ainda assim, as duas estruturas permaneceriam separadas. Seria exatamente nesse nível que estaria situada a afinidade eletiva de Weber.

No terceiro nível, "a articulação, combinação ou 'aliança' entre os parceiros pode ter como resultado diferentes modalidades de união: a) a que se pode chamar de "simbiose cultural”, em que as duas figuras permanecem distintas, mas são organicamente associadas; b) a fusão parcial; e c) a fusão total." (Löwy, 1999, p. 44).

No quarto nível, teríamos "a criação de uma figura nova, a partir da fusão dos elementos constitutivos" (Löwy, 1999, p. 44). Para Löwy, é difícil distinguir, de forma clara, os últimos dois níveis. Além disso, segundo ele, "estes dois últimos níveis da afinidade eletiva, sugeridos pelo sentido alquimista e 'Göetheano' do termo, estão ausentes da análise weberiana” (Löwy, 1999, p. 44).

Em todo esse processo, como foi visto, certas condições históricas jogam um papel fundamental, pois são elas que, de uma forma ou de outra, podem tanto favorecer o desenvolvimento do processo quanto obstá-lo. Segundo Löwy, faz-se "necessária uma determinada 
constelação [...] de fatores históricos, sociais e culturais para que se estabeleça [...] um processo de attractio electiva, de 'simbiose', de seleção recíproca, de reforço mútuo e, mesmo, em certos casos, a fusão de duas figuras espirituais" (Löwy, 1999, p. 45).

Löwy defende que o conceito de "afinidades eletivas" pode ser aplicado a variados domínios, permitindo que se compreenda "certo tipo de conjunção entre fenômenos aparentemente disparatados, no seio do mesmo campo cultural (religião, filosofia, literatura) ou entre esferas sociais distintas: religião e economia, mística e política, etc.” (Löwy, 1999, p. 45).

Dois pontos importantes precisam ser relevados. Um deles é que o processo de afinidades eletivas "dá conta de processos de interação que não resultam nem da causalidade direta, nem da relação 'expressiva' entre forma e conteúdo (uma forma religiosa sendo, por exemplo, a 'expressão’ de um conteúdo político ou social.” (Löwy, 1999, p. 45). O outro é que não se pode confundir afinidade eletiva com "simples parentesco ideológico inerente às diversas variantes de uma mesma corrente social ou cultural". Löwy chama a atenção para o fato de que a "eleição e a escolha recíproca, implicam uma distância prévia, uma distância cultural que deve ser coberta, uma $\stackrel{\infty}{\vec{a}}$ descontinuidade ideológica” (1999, p. 45).

กิ Ao analisar os usos que Weber faz do $\stackrel{\circ}{*}$ conceito de afinidades eletivas ao longo de sua obra, Löwy (2004, p. 96) identifica pelo menos dez modalidades nesse sentido. Três delas seriam relativas a formas internas em um mesmo campo. Uma interna ao campo religioso, que dá conta de relações entre formas religiosas distintas. Outra interna ao campo econômico nas relações entre o "espírito" do capitalismo e as formas de organização econômicas capitalistas. Por último, outra interna ao campo cultural.

As demais sete modalidades não seriam internas a apenas um campo específico, mas perpassariam campos distintos. Uma daria conta da relação entre as formas estruturais de ação comunitária e as formas concretas da economia. A quinta trataria da relação entre uma ética religiosa e um ethos econômico. A sexta, da relação entre formas religiosas e formas políticas. A sétima daria conta da relação entre estruturas econômicas e formas políticas. ${ }^{17}$ Uma oitava, entre classes sociais e ordens religiosas. A nona daria conta da relação entre visões de mundo e interesses de classes sociais. E, por último, aquela que trataria da relação entre estilos de vida de uma classe social e certos estilos de vida religiosos.

Löwy (2004) considera que essa tentativa de classificação tem sua importância, mas precisaria ser relativizada, na medida em que tais divisões não seriam estanques e sempre se poderiam fazer novos cotejos e cruzamentos. Na obra de Weber, teríamos mais indicações de como esse processo trabalha do que propriamente definições precisas sobre ele.

Com efeito, Weber lança mão de vários conceitos em torno do processo de afinidade eletiva. Por exemplo, lembrando que seriam sinônimos nem equivalentes, Löwy indica: adequação, parentesco interior, afinidade de sentido e congruência. De todo modo, Löwy aponta que Weber fornece indicações esparsas que podem garantir pistas importantes. Agregando algumas dessas passagens de Weber, Löwy constrói o seguinte sentido:

Quando dois elementos - por exemplo, um sistema social e um "espírito" cultural - são ligados por "um grau de adequação particularmente elevado”, entram em relação de afinidade eletiva. Eles se adaptam ou se assimilam reciprocamente (aneindander anzugleichen trachten), até que, finalmente, "o desenvolvimento de uma íntima e sólida unidade se instale”. Ou então, o nível de Wahlverwandtschaft entre uma ação comunitária e uma forma de economia depende do tipo de vínculo ativo que se estabelece entre os dois: "se e com qual intensidade eles favorecem reciprocamente sua existência ou, ao contrário, a entravam ou excluem; são reciprocamente ‘adequados' ou 'inadequados'. Nós falaremos com frequência de tais relações de adequação” (Lowy, 2004, p. 99).

${ }_{17}$ Neste caso específico, Löwy (2004) indica que o único exemplo de uso seria de uma afinidade "negativa", por exemplo, entre capitalismo e democracia, que ele considera bastante significativo. 


\section{ALGUMAS REPERCUSSÕES}

O esforço de elaboração e uso do conceito de afinidades eletivas por Löwy trouxe contribuição importante e reconhecida nas discussões sobre o tema. Löwy está certo ao afirmar que não se produziu um debate propriamente dito sobre o conceito em questão. Contudo não se pode deixar de indicar que seu trabalho produziu efeitos no campo.

Para o que nos tange aqui em termos temáticos, sobre o conceito de "afinidades eletivas”, sua elaboração e operação por Löwy, Boer (2010), partindo de uma posição diametralmente oposta, dedica todo um capítulo de seu trabalho sobre Marxismo e Teologia às contribuições de Löwy aos estudos acerca da religião, dando ênfase exatamente aos aspectos de nosso interesse. Boer (2010) considera que Löwy, na tentativa de aproximar Marx de Weber, acaba por, em muitos momentos, colocar Marx em segundo plano, "tocando um segundo violino" para Weber.

O ponto central dos questionamentos de Boer (2010) sobre os desenvolvimentos de Löwy reside na indagação de se o uso da dialética, ${ }^{18}$ segundo ele desaparecida, ou ao menos bastante esmaecida, não daria conta, até de forma mais complexa e profunda, dos fenômenos com os quais se buscaria lidar via o uso da démarche das "afinidades eletivas".

Outro ponto, aí relativo diretamente à tentativa de elaboração do conceito, Boer (2010) indaga se os níveis de "afinidade" avançados por Löwy seriam ou não sequenciais em termos de seu ordenamento e acerca da importância da "novidade" surgida a partir daí, que Löwy teria trazido da herança alquimista da trajetória do conceito, também incorporada por Goethe, embora, nesse particular, como

${ }^{18}$ Nesse sentido, Boer (2010, p. 165) menciona, por exemplo, as contribuições de Louis Althusser e seu "esforço bastante conhecido de dar novo sentido às várias esferas da cultura, política, religião, educação, justiça e economia enquanto domínios semiautônomos que interagem com outros. O econômico, então, se tornaria o domínio determinante apenas em última instância”. Para Boer (2010), a afinidade eletiva seria um modo de falar dessas relações dialéticas entre essas zonas semiautônomas. indicado pelo próprio Löwy, não presente em Weber.

A própria análise dialética deveria ser aplicada à trajetória proposta por Löwy acerca do percurso do conceito da alquimia à sociologia. Isso teria sido feito sem uma maior análise desse trajeto, de seus porquês, de suas próprias "afinidades" e "atrações".

Boer (2010, p. 166) critica também a forma como a "afinidade eletiva" é construída por Löwy. Ele chama a atenção para o fato de que, ao incorporar de Weber a ideia de um procedimento analítico via a construção de tipos ideais, Löwy se pautaria por um tipo de construção em que as duas pontas da relação tenderiam a ser iguais e autônomas, vindo em pares e com histórias que não são exploradas em grande detalhe. Assim, temos que o messianismo judeu é um tipo ideal, assim como os judeus intelectuais do final do século XIX, bem como a teologia da libertação o é. Dessa forma, os parceiros possíveis para a afinidade eletiva são, invariavelmente, duas entidades distintas que entram em contato através de um processo de escolha mútua. Em outras palavras, mais do que dois monólitos inertes de madeira, agência e decisões conscientes de engajar são cruciais. E se esses monólitos não forem tão iguais, ou até que um seja bem mais forte que o outro? Ele não dominaria a afinidade eletiva fazendo dela algo muito menos eletivo?

De todo modo, apesar de suas críticas, Boer (2010, p. 167-168) considera a possibilidade de uso do "método" da afinidade eletiva. Contudo, de seu ponto de vista, ele considera que isso teria utilidade para pensar o encontro de dois corpos de pensamento e ação e quando esse engajamento tem lugar a partir da escolha consciente dos participantes nesses movimentos. Para ele, o uso do conceito de afinidades eletivas, para ser útil, deveria incluir, necessariamente,

... fatores tais como parceiros desiguais, a possibilidade de padrões complexos de influência que se movam em ambas direções, a presença de mais de 
dois tipos ideais e de um movimento para além dos tipos ideais no sentido de fronteiras permeáveis entre eles, e a história dos mesmos prévia à interação (Boer, 2010, p. 167-168).

Por seu turno, ao analisar os intérpretes de Weber acerca da questão das "afinidades eletivas”, McKinnon (2010, p. 111), dialogando diretamente com os trabalhos de Löwy, chama a atenção para o fato de que, ainda que ele argumente que Weber teria derivado

... a noção de afinidade eletiva do uso metafórico feito por Goethe, ele mudaria sua atenção para o sentido do termo em uma tradição da química que, de há muito, havia perdido circulação na época de Weber. Mais ainda, Löwy complica a questão ao tentar entender o termo em todos os trabalhos de Weber de forma sinóptica, sem dar devida atenção à questão de como o conceito pode ter mudado nos textos de Weber ao longo do tempo (McKinnon, 2010, p. 111)

De toda forma, McKinnon (2010) reconhece que Löwy está correto ao assinalar que a analogia química é central para a compreensão do conceito de afinidade eletiva em Weber. Contudo, como para outros interpretes de Weber sobre a questão, McKinnon (2010) aponta para o fato de que todas essas análises poderiam ter se beneficiado de uma atenção mais detalhada à fonte das três origens reconhecidas da analogia de Weber: o romance Afinidades Eletivas, de

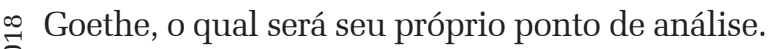

Já a crítica feita por Duran (2014) parte da perspectiva de que "afinidades eletivas", que portaria um alto rendimento literário, seria mais uma "noção" do que propriamente um "conceito". Em sua visão, seria difícil tirar vantagem, mais do que qualquer outra coisa, para além de uma dimensão essencialmente descritiva em seu uso. Ela teria, por certo,

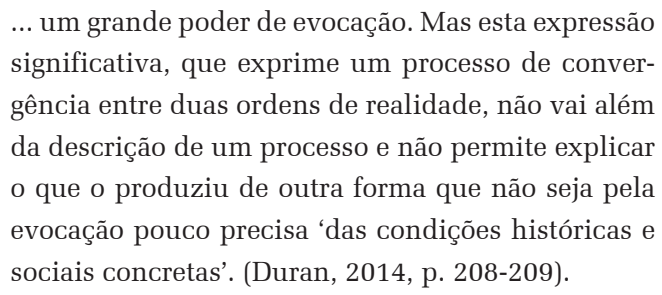
significativa, que exprime um processo de convergência entre duas ordens de realidade, não vai além da descrição de um processo e não permite explicar o que o produziu de outra forma que não seja pela evocação pouco precisa 'das condições históricas e sociais concretas'. (Duran, 2014, p. 208-209).

Nesse sentido, segundo Duran (2014), seria pouco suficiente entabular uma distinção de níveis ou graus de afinidade sem fornecer uma devida justificação. Ele considera a potência real de evocação da noção, contudo sinaliza para o fato de que "ela dá conta de uma situação, que ela não explica, ao mesmo tempo em que dá espaço para muitas flutuações em seus usos potenciais." (Duran, 2014, p. 209).

De forma sintética, essas leituras críticas das formulações de Löwy diriam o seguinte: McKinnon (2010) argumenta que teria sido mais interessante analisar uma possível dinâmica, e seu desenvolvimento e mudança no tempo, nas formas de operação de Weber com o conceito. Tanto McKinnon (2010) quanto Boer (2010) assinalam o interesse e a busca pela remota origem e fundamentação dada pelos alquimistas para o processo de "afinidades eletivas". Fazendo uma análise mais direta dos elementos pelos quais Löwy constrói sua definição de "afinidades eletivas", Boer (2010) aponta o que seriam suas limitações, inclusive indagando se o método dialético não daria conta do que se buscaria com as "afinidades eletivas", bem como sugere possíveis novos elementos para essa elaboração e uso renovado do procedimento. Já Duran (2014) chamaria a atenção para as especificidades e os limites do uso da noção e, assim, para as dificuldades apresentadas pelas tentativas de (re) elaboração da mesma.

\section{CONSIDERAÇÕES FINAIS}

O trabalho de elaboração e uso do conceito de "afinidades eletivas" tem sido uma contribuição importante de Löwy para o pensamento sociológico, concorde-se ou não com seus resultados. Seus estudos e seu engajamento político têm trazido essa marca. A literatura sobre o tema reconhece isso de uma forma ou de outra, seja referenciando seu trabalho e incorporando sua perspectiva, seja, ainda, ao criticá-la.

Ao observar o conjunto de trabalhos que tratam especificamente da questão em tela, percebe-se que Löwy foi o único autor até aqui que, 
para além da percepção do que teria sido uma baixa definição por Weber de um conceito e (ou) de percorrer sua história e suas influências, dedicou-se a um esforço teórico de elaboração sobre essa lacuna. E não apenas isso: Löwy trata de tentar operar com tal elaboração, fazendo-a trabalhar em termos de reflexão e pesquisa.

Thomas (1985), em artigo anterior aos esforços de Löwy, chama a atenção para o fato de que, mesmo seguindo caminhos diferentes, muitos intérpretes de Weber, que indicaram sua indefinição sobre as "afinidades eletivas", teriam sido mais imprecisos que ele. Não se poderia dizer que Löwy seja impreciso em termos de suas definições sobe o conceito de "afinidades eletivas". Pelo contrário, há uma tentativa, como vimos, bastante efetiva de seu detalhamento, de definição de níveis etc. E sua extensa produção nessa área deixa explícita sua tentativa também de operar com o conceito que elabora.

Vimos como a literatura não tem muitos consensos sobre a questão das "afinidades eletivas", salvo talvez acerca de sua centralidade e pouca definição na obra de Weber, e da história percorrida por sua formulação e uso nas diversas áreas. Uns consideram que "afinidades eletivas" seria um método; para outros, seria um conceito; para alguns, apenas uma noção. Nesse campo diverso, Löwy produziu efeitos interessantes, que podem servir tanto como porto seguro de chegada quanto para novas partidas e aventuras.

Recebido para publicação em 20 de janeiro de 2018 Aceito em 28 de maio de 2018

\section{REFERÊNCIAS}

ALLEN, K. Weber: sociologist of empire. London: Pluto Press, 2017.

BESANCENOT, O.; Löwy, M. Afinidades revolucionárias. Nossas estrelas vermelhas e negras. Por uma solidariedade entre marxistas e libertários. São Paulo: Edunesp, 2016.

BOER, R. Criticism of theology : on marxism and theology III. Leiden: Brill, 2010.

DURAN, P. Cage d'acier ou necessité de fer, peut-on parler d'un marxisme wébérien? À propos d'un ouvrage de Michael Löwy. L’Année Sociologique, Paris, v. 64, n. 1, p. 205-214, 2014.
GERTH, H. H.; MILLS, C. W. Introdução: o homem e a obra. In: Weber, M. Ensaios de sociologia. Rio de Janeiro: LTC Editora, 1982.

HOWE, R. H. Max Weber's elective affinities: sociology within the bounds of pure reason. Am. J. Sociol., Chicago, v. 84, n. 2, p. 366-385, Sept. 1978.

KALBERG, S. On the Neglect of Weber's protestant ethic as a theoretical treatise: demarcating the parameters of postwar american sociological theory. Sociological Theory, Washington, v. 14, n.1, p. 49-70, Mar.1996.

LÖWY, M. Weber et Marx: notes critiques sur un dialogue implicite. In: . L'Homme et la société. [s.l.; s.e], 1971. p. 73-83. (Lukács Hegel histoire et sociologie, n .20).

As Aventuras de Karl Marx contra o barão de münchhausen: marxismo e positivismo na sociologia do conhecimento. São Paulo: Busca Vida, 1987.

. Rédemption et utopie: le judaisme libertaire em europe centrale. Une étude d'affinité élective. Paris: PUF, 1988.

Weber against Marx? The polemic with historical materialism in the protestant ethic. Science $\mathcal{E}$ Society, Montague Street, v. 53, n.1, p. 71-83, 1989.

LÖWY, M. Marxisme et Christianisme em Amérique Latine. In: . Revue Tiers Monde. Religion, pouvoir et société dans le Tiers Monde. France, July-Sept 1990. t. 31, n. 123, p. 667-682.

Figures of weberian marxism. Theory and society, [s.1], v. 25, n. 3, p. 431-446, June 1996.

LÖWY, M. Le concept d'affinité élective en sciences sociales. In: .Critique internationale: sciences po university press. [s.l.; s.e.], 1999. n.2, p. 42-50.

Marx, Weber and the critique of capitalism. Logos, [s.1], v.1, p. 77-87, 2002.

Le Concept d'affinité élective chez Max Weber. Max

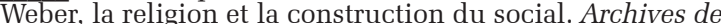
sciences sociales des religions, France, EHEES, n. 127, p. 93-103, July/Sept. 2004.

Crise ecológica, crise capitalista, crise de civilização: a alternativa ecossocialista. Caderno CRH, Salvador, v. 26 , n. 67, p. 79-86, jan./abr. 2013.

Marx, Engels, and ecology. Capitalism nature socialism, France, v. 28, n. 2, p. 10-21, 2017.

MCKINNON, A. Elective affinities of the protestant ethic: Weber and the chemistry of capitalism. Sociological Theory, Washington, v. 28, n. 1, p. 108-126, 2010.

NIELSEN, D. A. The incredible shrinking protestant ethic. Int J Polit Cult Soc, [s.1], v. 16, n. 4, p. 587-598, 2003.

PIERRUCCI, A. Apresentação. In: Weber, M. A ética protestante e o "espírito" do capitalismo. São Paulo: Companhia das Letras, 2004.

Economia e sociedade: últimos achados sobre a "grande obra" de Max Weber. Revista Brasileira de Ciências Sociais, São Paulo, v. 23, n. 68, p. 41-51, out.2008.

SCHLUCHTER, W. Éléments d'un programme de recherche wébérien. Revue française de sociologie, Paris, Editions Technip \& Ophrys, v. 46. p. 653-683, 2005.

THOMAS, J. J. R. Ideology and Elective Affinity. Sociology, Sage, v. 19, n. 1, p. 39-54, Feb.1985.

WEBER, M. The Protestant ethic debate: Max Weber's replies to his critics, 1907 to 1910. Chalcraft, D. ; Harrington, A. (Orgs.) Liverpool: Liverpool University Press, 2001.

A ética protestante e o "espírito" do capitalismo. São Paulo: Companhia das Letras, 2004.

A "objetividade" do conhecimento nas ciências sociais. In: Cohn, G. (Org.) Marx Weber: sociologia. São Paulo: Editora Ática, 2008. p. 79-127. 


\section{A MARXISM OF ELECTIVE AFFINITIES: the sociological adventure of Michael Löwy}

\section{Marco Aurélio Santana}

The article analyses the Michael Löwy's work upon the concept of "elective affinity" used by Max Weber. We draw upon Löwy's articles presenting his attempt to build an effective contribution to a more clear definition and use of the concept. The article points out some of the arguments put forward by his critics displaying what would be Löwy's formulation limits. As an introduction we present the sociological context of the most famous appearance of the concept in the Max Weber's book The protestant ethics and the "spirit" of capitalism which has been serving for Löwy's research and developments.

Keywords: Elective affinity. Michael Löwy. Max Weber. Protestant ethics. Social theory.

\section{UN MARXISME DES AFFINITES ELECTIVES: l'aventure sociologique de Michael Löwy}

\section{Marco Aurélio Santana}

L'article analyse le travail d'élaboration de Michael Löwy a propos du concept de "affinités électives", utilisé par Max Weber. Dans ce registre, présente ses contributions pour une meilleur définition et opérativité de cet concept, ainsi que quelques répercutions qu'on indiqué ses possibles limites en termes d'élaboration et mise en travail. Avant, en guise de préambule, l'article fait une présentation du contexte sociologique de ses occurrences meilleur connu, a partir du livre Létique protestante et l'esprit du capitalisme (EPEC), de Max Weber, que sert de base aux investissements réflexifs de Löwy.

Mots-CLÉs: Affinités électives. Michael Löwy. Max Weber. Éthique protestante. Théorie sociale. 